\title{
Understanding cultural influences on back pain and back pain research
}

Nicholas Henschke*, BAppSc(Physiotherapy)(Hons), PhD.

Musculoskeletal Division, The George Institute for Global Health, Sydney, Australia

nhenschke@gmail.com; Phone: +4917687611510

Eva Lorenz, Dr. sc. hum. Dipl.-Inform. Med.

Institute of Medical Biostatistics, Epidemiology and Informatics, University Medical Center of the Johannes Gutenberg University Mainz, Mainz, Germany

Eva.Iorenz@uni-mainz.de; Phone: +49613117 3121

Roman Pokora, Dipl. Soz., MSc(Epidemiology)

Institute of Medical Biostatistics, Epidemiology and Informatics, University Medical Center of the Johannes Gutenberg University Mainz, Mainz, Germany

pokora@uni-mainz.de; Phone: +4961313938746

Zoe A Michaleff, BAppSc (Physiotherapy)(Hons), PhD.

Arthritis Research UK Primary Care Centre, Research Institute for Primary Care \& Health

Sciences, Keele University, United Kingdom

z.michaleff@keele.ac.uk; Phone: +4401782734853

Jonathan N. A. Quartey, MSc(Physiotherapy), MSc(Health Professions Education)

Department of Physiotherapy, School of Allied Health Sciences, College of Health Sciences, University of Ghana, Ghana

jquartey@chs.edu.gh

Vinicius Cunha Oliveira, PhD, BAppSc(Physiotherapy and Sports and Exercise), MSc

Pós-Graduação em Reabilitação e Desempenho Funcional, Universidade Federal dos Vales do Jequitinhonha e Mucuri, Diamantina, Brazil

viniciuscunhaoliveira@yahoo.com.br; Phone: +553835328982

*corresponding author

Word count: 7970 words 


\section{Abstract}

Low back pain is highly prevalent and places a considerable burden on individuals, their families, and communities. This back pain burden is unequally distributed around the world and also within populations. Clinicians and researchers addressing back pain should be aware of the cultural, social, and political context of back pain patients and how this context can influence pain perception, disability, and health care use. Culture, which influences the beliefs and behaviour of individuals within a social group, could be considered an important contributor to the unequal distribution of back pain. However, there is paucity of highquality research exploring the influence of culture on the experience and management of back pain. Further development and testing of specific tools, assessment methods and communication strategies are needed, to improve our understanding of how cultural practices, values, and identifications affect those dealing with back pain.

\section{Key words}

Culture; back pain; social determinants; ethnicity; race 


\section{Introduction}

Low back pain is highly prevalent and places a considerable burden on patients, their families, and society. It is estimated that up to $85 \%$ of the general population will suffer from low back pain at one point in their life and over $10 \%$ will suffer from long-lasting chronic pain [1]. In the majority of patients low back pain negatively affects overall perceptions of general health, interferes considerably with everyday activities, is associated with depressive symptoms, and dramatically and negatively affect relationships and interactions with others

[2]. The World Health Organization (WHO) sponsored Global Burden of Disease study reports that of all health conditions, low back pain was the greatest contributor of years lived with disability (YLD), accounting for $10.7 \%$ of all YLD [3] and responsible for 83 million disability adjusted life years (DALYs).

While low back pain has traditionally been characterised as a symptom of underlying pathology, developments in the understanding of its pathological processes [4] coupled with recognition of the enormous burden on individuals, communities, and healthcare systems [3], has led to it being studied as a disease in its own right [5]. The high prevalence of low back pain in the general population is coupled with a lack of effective primary care treatments [6] and little agreement on suitable targets for prevention [7]. The effect of low back pain-related disability on quality of life and its economic impact worldwide has resulted in calls for it to be viewed as a public health problem $[1,8,9]$. Other major public health problems such as obesity, heart disease and cancer are often the focus of large-scale epidemiological studies to understand their underlying determinants, or "distal" risk factors, which can in turn guide prevention strategies. Work of this nature has, to date, been lacking for low back pain. Considering health problems from a population perspective has shown 
that they tend to be unequally distributed, with those members of society who are the least advantaged having the highest proportion of suffering [10]. Strategies for the prevention of non-communicable diseases (NCDs) have therefore developed to include comprehensive approaches that consist of interventions directed not just at individuals, but the whole population.

From a social determinants of health perspective [10], many of the key determinants of low back pain are likely to be the social and economic conditions in which people work and live. The emphasis should therefore move to research directed at the structural, social and cultural factors that shape the experience of pain. The prevailing biopsychosocial model of pain implicitly supports the notion that societal, lifestyle, and biological explanations of pain are interconnected and mutually reinforcing [11]. However, most research efforts to date are directed towards the biological and psychological aspects of pain, with the social aspect largely overlooked. In particular, the cultural influences of societies are often underestimated determinants of their population health and well-being $[12,13]$. This is as true for modern Western culture as it is of other cultures. Emerging evidence from a range of disciplines has suggested that cultural influences can affect health and well-being through their impacts on psychosocial factors, beliefs, and attitudes. In this article, we review the evidence linking culture and back pain, and propose a number of clinical and research implications.

\section{Culture and acculturation}

Culture refers to an integrated pattern of beliefs and behaviour within a social group, that coexists with the individuality of each member. At any point in time, individuals are able to 
identify themselves with particular social groups, for example, based on ethnicity, gender, nationality, common interests, or sexual orientation [20]. The ability to identify with more than one group makes the culture of an individual dynamic and constantly evolving, and particularly challenging to assess when performing research. Race, ethnicity, migration background, and culture are often used synonymously in published health research, but represent distinct concepts [14]. Race is based on specific genes that identify major groups of people by ancestry and heritable physical characteristics $[15,16]$. Ethnicity refers to people within a society who share a common language, religion, culture and experience [15, 17], whereas culture is defined by the United Nations Educational, Scientific and Cultural Organization (UNESCO) as "the set of distinctive spiritual, material, intellectual and emotional features of society or a social group, and that it encompasses, in addition to art and literature, lifestyles, ways of living together, value systems, traditions and beliefs" [18]. Culture is sometimes, but not always, synonymous with nations and national boundaries. Groups that are similar on one dimension of culture (e.g. those that share a common language) are not necessarily similar on other cultural dimensions [19].

In the modern world, international travel and global media have made nearly all societies multicultural to some degree. . The term "acculturation" is used to describe the process of encountering another cultural group, for example, through migration from one country (i.e. the heritage culture) to another (i.e. the receiving culture), and the subsequent changes this can impart $[15,19]$. Acculturation to the receiving culture does not necessarily imply a loss or rejection of the heritage culture; people can identify with aspects of both cultures simultaneously [15]. While beliefs and practices are shared by communities, there is also 
considerable intra-cultural variation that is influenced by factors including the social, economic and political circumstances within which an individual exists.

\section{Culture and health}

Both health and illness are cultural concepts because our culture shapes how we perceive, experience, and manage health and illness [21]. Health behaviours such as when and where to seek help, how long to remain in care, and how to evaluate treatment success are influenced by culture $[21,22]$. Health itself is defined in many ways across cultural groups. Since its inception in 1948, the World Health Organization (WHO) has defined health as a state of complete physical, mental, and social well-being [23]. Other groups conceptualise health in broader ways [24]. For example, Ayurveda, the widely practiced Indian system of medicine, views health as a harmony between the body, sense organs, mind, and soul [25]. Similarly, Traditional Chinese Medicine views health as a balance between "yin" and "yang", the two complementary energies of the universe. When these two energies fall out of harmony, disease develops [25].

More attention, in both clinical and research settings, needs to be paid to the complex role of culture in health $[12,13]$. Health and disease are multi-factorial and defined by a person or group interacting with the physical, social, and economic environment. This complexity often results in culture and cultural influences being largely underestimated by health research [26]. Instead of considering the complex influence of culture, most health researchers measure simpler, more direct determinants of health such as personal circumstances or psychosocial status. However, the circumstances and psychosocial status of an individual are strongly influenced by culture, and this influence can affect people 
differently and contribute to specific problems that only some experience. Drawing from different disciplines, such as anthropology and social science, provides a range of measures and indicators of cultural influence which can facilitate the conduct of empirical studies which quantify the association between culture and health. There is now emerging literature on measurement of cultural practices (e.g. language use, media preferences, and cultural customs and traditions), cultural values (e.g. belief systems associated with a specific context or group, such as the value placed on the individual person or the family), and cultural identifications (e.g. attachments to social groups, and the influence of these attachments) [15].

\section{Social determinants of back pain}

Prior to exploring the influence of culture on the experience and management of back pain, sufficient attention needs to be paid to the theoretical basis behind how culture can affect health in general, and pain perception and disability in particular. Population-level risk factors for disease have been increasing in prominence as a growing amount of research has revealed how the structure of societies, through social, economic and political mechanisms, can affect population health [10]. Culture has an influence on individuals at a populationlevel and can also contribute to the definitions of social class or status within a society. Based on their social status, individuals can experience differences in exposure and vulnerability to health conditions. Public health problems have been shown to be unequally distributed in society, with the most disadvantaged people having the greatest burden of disease [10]. An association between social inequality, determined by a person's socioeconomic position relative to others, and the prevalence of musculoskeletal pain has been proposed by a number of authors [27-30]. It has also been suggested that people living 
in adverse socioeconomic circumstances may not only be more likely to experience pain, but more severe pain and disability $[27,30,31]$.

In 2008, the WHO established a Commission on Social Determinants of Health to discuss how social inequality can affect health around the world [32]. The commission developed a framework (Figure 1) which shows how social, economic and political mechanisms give rise to a set of socioeconomic positions, whereby populations are stratified according to income, education, occupation, gender, race or ethnicity, and other factors. These socioeconomic positions in turn shape specific determinants of health status (intermediary determinants). Based on their respective social status, individuals experience differences in exposure and vulnerability to health conditions. Illnesses can then "feedback" on a given individual's social position, for example by compromising employment opportunities and reducing income [32].

One explanatory model linking socioeconomic inequality and health has been termed the psychosocial environment interpretation [33]. It proposes that psychosocial factors are paramount in understanding the health effects of inequality, and that perceptions and emotions are important influences on health outcomes. This theory argues that socioeconomic inequality can affect health through perceptions of place in the social hierarchy [34] or through persistent exposure to harmful social and economic conditions [35]. Exposure to social inequality produces negative emotions which are associated with depression, anxiety, isolation, insecurity, and lack of control over one's life [10,33]. Whether psychosocial factors affect health only through stress-induced behaviours, such as smoking [33] or also act via direct effects on the neuroendocrine and immune systems remains 
contested. However, this does not affect the case for taking culture into account as the role of perceptions, expectations and emotions in health will clearly be influenced by culture.

This theory, however, lacks reference to the material conditions that each individual interacts with on a day-to-day basis. The poorer health in deprived populations could reflect a combination of negative exposures (as per the theory above) and a lack of resources held by individuals, along with under-investments across human, physical, health, and social infrastructure. Under this framework, one would predict a direct relationship between social disadvantage and both the frequency and the severity of health conditions. Some initial analyses have provided supporting evidence for this hypothesis in musculoskeletal pain. In a study from the United Kingdom, area-level deprivation was independently associated with the prevalence of pain, as well as pain-related disability in older adults [28]. Another study from Austria utilising national health survey data found that even at the same intensity of pain, those in the lowest socioeconomic group reported feeling two to three times as disabled as compared to the highest group [36]. Blank and Diderichsen (1996) found social inequalities in both self-reported frequency and intensity of a variety of common symptoms in a Swedish population [37]. Their results lend support to the hypothesis of "double suffering" - that lower classes both have more long-term illnesses and also experience these illnesses with greater intensity [31].

\section{Influence of culture on pain perception, disability, and management}

Pain is a universal experience of the human existence and is found among people of all ages and social classes, as well as in all cultures [31]. However, there is inequality in the pain experience between individuals and also between cultural groups [38]. Most individuals will 
try to avoid pain in general, though when they do get pain, culture influences what is expected of them, how to act, and what is acceptable to others [19]. Like many other physiological phenomena, pain has specific social and cultural significance, and reactions to pain must be understood in light of this significance. An individual's culture may encourage avoidance of pain, or acceptance as a part of the life experience. In this way, culture becomes the conditioning influence in the formation of the individual reaction patterns to pain [33].

The aetiology of many pain conditions, such as back pain, is unclear and the identification of risk factors has been hampered by shortcomings in epidemiological study methods [1]. As a result, recent back pain research has focussed on understanding the characteristics of patients that affect recovery, chronicity and recurrence [39]. Most early studies on the causes of back pain concentrated on physical exposures, such as manual material handling, repetitive movements, awkward postures, and vibration [1]. More recently, psychological risk factors - such as pain attitudes, beliefs and emotional responses (e.g. pain catastrophizing) - have been the focus. While this has resulted in the development of psychological theories and interventions to address maladaptive pain beliefs and behaviours [40], much less is known about the broader social, political and cultural context of back pain. It seems unlikely that individual-level risk factors can fully explain the variation in occurrence of pain conditions and associated disability that has been observed between and within countries over time [41].

Numerous multinational studies and reviews have identified large variations between countries in estimates of the prevalence of back pain [1, 3, 41-43]. Often, the lack of 
standardised methodology in these studies limits direct comparisons of prevalence across country and obstructs the identification of common risk factors [1]. In a secondary analysis of a large multinational study, Swain et al [44] reported the prevalence of back pain in adolescents ranged from $27.7 \%$ to $50.5 \%$ across 28 countries in Europe and North America (Figure 2). In contrast to other studies, the use of a multinational survey allowed comparisons using validated, comparable survey methods for the prevalence of back pain. Nevertheless, the differences in prevalence persisted even after adjusting for age, sex and socioeconomic status [44]. Systematic reviews have also illustrated that the prognosis of back pain varies across country, with Australian cohorts reportedly having a more favourable prognosis than those from Europe and the United States $[45,46]$. The differences in prevalence and prognosis across countries has prompted the hypothesis that pain and resultant disability are importantly influenced by culturally-determined health beliefs as well as by physical activities and mental health [47].

Several observations provide support for an important role of health beliefs in back pain. For example, in longitudinal studies of individuals with back pain, negative beliefs about prognosis have proved predictive of their persistence $[48,49]$. In Victoria, Australia, a statewide community-based intervention aimed at modifying people's beliefs and expectations about back pain was followed by a reduction in morbidity that was not paralleled in a control state [50]. A unique study investigating the prevalence of back pain in Germany reported that shortly after Germany's reunification in 1990, the prevalence of back pain was clearly different between East and West with lower rates in the East [51]. Over the next 13 years, while prevalence rates remained high in West Germany, the gap in prevalence between East and West decreased to nearly zero. Behavioural and occupational risk factors could only 
partly explain the change in prevalence. While unconfirmed, the authors suggested that harmful back-related beliefs and attitudes were transmitted from West to East Germany via mass media and personal contacts [51].

\section{Pain perception}

Effective assessment and management of back pain depends upon communication between patients and clinicians that is free from both conscious and unconscious bias. One of the main barriers to satisfactory treatment of pain are the underlying assumptions that are made by individual clinicians during consultations, for example, that some cultures are insensitive to pain or that others are overly-sensitive [10]. With regard to the perception of pain, considerable research has been performed in order to investigate racially or ethnicallybased genetic differences in pain expression [14]. What must be noted is that these findings have implications for understanding individual differences in pain expression rather than differences between groups [10]. Differences in pain behaviours among groups are much more likely due to factors such as beliefs and attitudes about pain, education, economic status, and access to medical and social support, than to racial or ethnic composition $[10,14$, 38].

In terms of pain perception, there is the potential for culture to influence and potentially lead to differences in monitoring, symptom attribution, and somatization [10]. Monitoring refers to the attention individuals pay to internal bodily events, while symptom attribution refers to the extent to which individuals consider bodily events to indicate dysfunction rather than a normal biological process. Somatization is the extent to which psychological distress contributes to increased reports of physical discomfort [10]. These features, as well 
as other psychological processes are known to influence the assessment of pain in a clinical or research setting, and could potentially explain some of the differences in reporting of pain according to self-reported ethnicity [52]. Of interest are also which facets of a pain experience are communicated verbally and which ones non-verbally, and whether cultural groups differ in the way they use these channels. Clinicians may interpret overt pain expressions such as crying and moaning as an indication that patients are dramatic, emotional and unable to manage pain. However, in certain cases the same behaviour may help the patient to relieve their pain rather than function as a request for intervention [10].

The association between culture, pain perception, and language has been studied in more depth and highlights the lack of sensitivity of common outcome measurements used in clinical and research settings. In the English language, pain quality is often described through metaphors, such as "burning" or "sharp" pain, which are reflected in outcome measures such as the McGill Pain Questionnaire [53]. Other languages, such as Japanese, do not use such terms and instead pain qualities are described along several axes, including intense vs. not intense, deep vs shallow, and temporally extended vs temporally bounded [54]. With language playing an important part in the expression of pain, recent research has focussed on improving cross-cultural adaptation of back pain outcome measures for clinical and research purposes $[55,56]$. A systematic review of cross-cultural adaptations, however, identified 40 back pain outcome measures of which only 15 had been adapted to a new language [56]. After specifically searching for 35 different languages, only 19 were represented in the search results. The authors reported that from 1400 possible adaptations, only 61 have been completed. The psychometric testing of the adapted questionnaires was 
also considered sub-optimal, usually involving an assessment of reliability and construct validity only [56].

\section{Disability}

The concept of disability, including pain-related disability or functional status, also varies from one culture to another. It has been argued that the disadvantages that individuals with impairments have (such as back pain) are caused mainly by the way that social environments adjust to disability [13]. Social and psychosocial factors underlie how one can live productively with what others might label a disadvantage. The International Classification of Functioning (ICF) is the WHO's framework for measuring health and disability [57]. The ICF sees disability as a "mainstream" and universal human experience, and asserts that every person experiences some degree of disability as a result of natural decline in health that occurs over the lifespan [21]. By including contextual factors, the ICF allows clinicians and researchers to appreciate the impact of the cultural context on a person's functioning. However, the ICF core set has long been considered to be too large of an outcome measure to be of practical use in clinical studies [58].

One multinational study that was established to explore the contribution of culturallydetermined health beliefs and other risk factors to disability arising from common musculoskeletal complaints is the Cultural and Psychosocial Influences on Disability (CUPID) study [59]. The study demonstrated large variation among occupational groups in the occurrence of disabling musculoskeletal conditions. The variation was seen even in groups carrying out similar occupational activities, and was only partially explained by established individual risk factors or by socioeconomic influences such as systems of compensation for 
work-related illness and injuries, and financial support for health-related incapacity for work. The authors suggest that widespread awareness of pain-related disability and adverse beliefs about it could encourage its incidence in a workforce [59].

\section{Pain management}

Apart from pain perception and behaviours, culture has a vital influence on illness beliefs, health care practices, help-seeking activities, and receptivity to medical care interventions. Individuals within certain cultural groups may not feel that back pain is a sufficient reason to seek care [38]. High-quality pain care requires that each patient be viewed as an individual with many characteristics, including a particular cultural background. If cultural factors are not taken into account, the provision of care may be ineffective at best, and at worst harmful. In order to maximise the chance of effective pain management, within each cultural group pain must be viewed from the perspective of its psychologic, social, and spiritual significance.

While the societal and individual burden of back pain is substantial, a minority of patients within a population experience a much larger share of the pain burden $[27,36,60]$. Recent studies suggest that this larger pain burden may not only be in terms of incidence and prevalence rates, but also due to a greater likelihood of under-treatment of pain [38]. Despite national and international clinical guidelines for back pain and numerous educational interventions for clinicians and patients, racial and ethnic disparities in assessment and treatment of pain have been found in all settings (i.e. postoperative, emergency room) and across all types of pain (i.e. acute, cancer, chronic non-malignant, and experimental) $[38,61]$. The literature suggests that the sources of these disparities are 
complex, involving patient (e.g. communication, beliefs, attitudes), health care provider (e.g. decision making), and health care system (e.g. access to pain medication, culturally appropriate information) factors $[38,61]$. The design and assessment of effective health care interventions to alleviate pain for culturally diverse patients, including indigenous peoples, immigrants, and refugees, presents a complicated task for health care professionals [62].

Further research is needed on the effectiveness of culturally sensitive interventions, applied to specific cultures who are most likely to benefit. This implies that certain alternative interventions need to be considered for some people to manage pain effectively [63]. For example, religion can be considered a possible instrument for the handling of pain in some patients who are believers [64], especially those who have spiritual beliefs about the cause of their pain. When we consider other social groups - such as athletes - where a culture exists of disregarding risk of physical harm, and pain and disablement are normalised [65], enforced rest or restricted activities may play an important role. However, many studies on pain management in cultural minorities are flawed as they rely on convenience samples, have small sample sizes, or collect data retrospectively $[20,38]$. In addition, researchers have not taken sufficient care in their studies to distinguish among ethnicity, culture, and race. It is ill-advised to lump all people of Asian extraction together into a single category; there are many cultural, linguistic, and religious differences among people of Chinese, Japanese, Malaysian, and Vietnamese backgrounds.

\section{Clinical implications}

Current pain assessment tools are not sufficient to ensure high quality of care for clients of different cultural backgrounds [66]. Clinicians must work closely with patients (and their 
families) in order to obtain accurate information about their pain and beliefs to provide culturally appropriate care. Strategies to assist clinicians in performing culturally appropriate assessment and management of pain include; utilising assessment tools to assist in measuring pain while appreciating variations in affective responses to pain, and being sensitive to variations in communication styles [66]. Clinicians must also recognise that communication of pain may not be acceptable within some cultures and appreciate that the meaning of pain varies between cultures. Finally, it is important that all clinicians develop a personal awareness of values and beliefs, including their own, which may affect responses to pain.

There is evidence that some clinicians unconsciously operate with perceived racial and cultural stereotypes, display limited cultural sensitivity, and hold assimilation beliefs $[20,67]$. This may influence the quality of care provided to patients from culturally and linguistically diverse backgrounds. In addition, clinicians tend to underutilise health interpreters for consultations and may display negative attitudes towards health interpreting services [68, 69]. For back pain in particular, clinicians should be aware of cultural barriers such as the unsuitability of manual therapy in some cultures [70], or whether self-management will be understood and effective for other cultures [70]. Cultural competence training shows promise as a strategy for improving the knowledge, attitudes, and skills of health professionals. This can involve learning about the cultural aspects of health and illness, recognition of personal biases against people of different cultures, and awareness of a responsibility to combat biases and discrimination in health care. A number of systematic reviews have been performed to synthesise the empirical evidence around cultural competency training for health professionals [71-73]. One large review of thirty-four studies 
[71] showed that there is good evidence that cultural competence training can improve the knowledge, attitudes and skills of health professionals. There was also some evidence that cultural competence training impacts patient satisfaction, but inconclusive evidence about the impact on patient adherence or patient health outcomes, and equity of services across groups.

\section{Communication and back pain management}

Good communication between patients and clinicians is fundamental to successful back pain management $[62,74]$. Effective communication improves satisfaction and well-being of patients by heightening respect, enhancing interpersonal relationships and improving compliance with treatment. Patients with back pain often desire an explanation of what is being done during a treatment session, information about the cause of pain, reassurance, and an opportunity to discuss other issues $[62,75,76]$. In order to identify cultural beliefs and attitudes about a patient's back pain experience, the communication practices of the clinician are vital [77]. Clinicians should seek to avoid passive styles of communication and instead facilitate patient discussion, for example, by using open questions, formulating a version of the patient's talk, and supportive non-verbal cues such as affirmative head nodding, to enhance patient participation. When clinicians provide reassurance and offer pain explanations without fully understanding a patients' beliefs, the result is weak patient alignment and in some cases explicit disagreement $[78,79]$. By comparison, reassurance accompanied with pain explanations consistent with the patient's pain beliefs produces stronger agreement [76, 77]. 
Language proficiency is relevant in studies of cultural influences because language limits the extent to which people can access health information and health care, communicate their health problems and questions, understand instructions, and participate in interventions [19]. A study from the Netherlands [80] confirmed that patients' cultural views, language proficiency and age were more important for satisfaction with care than ethnic origin or education [80]. Adopting more patient-centred and communication-focussed strategies may help to identify social and cultural factors that impact back pain severity and recovery [11, 81]. Applying more psychologically informed and individualised treatment plans may help to counter negative social factors, but whether these strategies can have an effect on cultural influences remains to be seen.

\section{Research implications}

Assessment of cultural influences in back pain research is lacking and very few studies are available on strategies to improve care for patients with back pain from various cultural backgrounds [70]. While many individual physical and psychological characteristics are measured as potential prognostic factors or indicators for treatment, the assessment of social or cultural influences is rare. There is a discrepancy between the biopsychosocial model, which includes the influence of social and cultural factors, and what is measured in back pain research. Researchers are often faced with decisions about which cultural influences to assess in a study and how to measure them. Numerous survey measures of cultural constructs exist, including measures of language usage and proficiency, behavioural acculturation to the receiving culture and to the heritage culture, biculturalism, ethnic identity, cultural values, and acculturative stress [19]. 
Due to the complex relationship between culture and health, it is important to make informed decisions about which scales to use based on theoretical mechanisms by which culture influences health. Many researchers emphasise the importance of measuring cultural practices, values, and identifications separately [19]. These phenomena evolve at different rates; for example, an immigrant can learn a new language and begin practicing new cultural behaviours without fully identifying as a member of that culture. If cultural practices, values, and identifications each potentially exert unique influences on the behaviour in question, they should be measured as separate constructs. Often, these constructs can be aggregated to the national level to conduct cross-cultural comparisons, or they can be studied at the individual level to examine variation in values within a culture [82]. In addition, several studies have concluded that a number of values are present across cultures $[19,83]$, such as the importance of the family versus the individual, respect for elders and authority figures, and gender role equality or differentiation. Depending on the goals of the research, researchers can use scales that were developed within and tailored to one specific culture, or scales reflecting more broadly-defined values [19].

\section{The importance of the cultural context}

Behaviour is influenced not only by an individual's cultural characteristics, but also by the surrounding cultural environments [84]. When measuring cultural influences on behaviour, researchers should also consider the cultural context of the neighbourhood, school, workplace, or general geographical area. This may include the demographic characteristics of the surrounding population, including race, ethnicity, and immigration status, and also shared social norms and values. The cultural context exists at multiple levels of analysis (e.g. micro-level contexts such as the family, meso-level contexts such as neighbourhoods, and 
macro-level contexts such as the political climate). Operationalisations of the cultural context may be drawn from surveys of attitudes, beliefs and values [26], but can also be based on objective data on, for example, social fragmentation (renting, mobility, unmarried people, single-person households) [85], or social integration (divorce rates, education, labour-force participation, family relationships, social interaction, religious participation, community involvement). In contexts where multiple cultures intersect, for example, in communities with large immigrant populations, both cultures should be evaluated [19].

Cultural influences on health behaviours and outcomes are complex. Advancing our understanding of these processes depends on comprehensive and valid understanding and measurement of cultural dimensions and their interactions across levels of analysis (micro to macro). Improved conceptualisation of cultural influences on health could lead to the development of more effective and culturally relevant health education and promotion programs.

\section{Summary}

Health and illness are determined by a convergence of many influences, including social, cultural, and biological factors. These factors affect individuals in different ways and can create inequality in the burden of disease within a population. Cultural influences affect individuals and groups in subtle and complex ways which are not often immediately apparent. Clinicians and researchers, therefore, need to be aware of the cultural, social, and political context of back pain patients, as well as their own cultural biases. Cultural practices, values, and identifications can influence the perception of back pain, how much disability results from an episode of pain, and what kind of health care is sought to manage pain. 
However, there are few high-quality studies exploring the relationship between cultural influences and back pain and fewer still on culturally appropriate communication and management. Future research needs to focus on the development and testing of specific tools, assessment methods, and communication strategies which are linked to theoretical models of cultural influences on health. In order to improve the lives of people suffering from back pain and reduce the burden on families and societies, cultural equality - treating others as different but equal - must become a priority. 


\section{Practice points}

- Clinicians and researchers addressing back pain should acknowledge their own cultural biases and examine how they impact patient care;

- Be aware of the cultural, social, and political context of back pain patients and how these can influence pain, disability, and health care;

- Collaborate with patients to understand the best treatment options for the specific situation

\section{Research agenda}

- Further development and testing of specific tools, assessment methods and communication strategies are needed, to improve understanding of cultural influences;

- Encourage more research into the cross-cultural measurement and comparability of subjective well-being data;

- Emphasise the importance of measuring cultural practices, values, and identifications separately in studies of back pain;

- Analytic strategies and choice of measures of cultural dimensions should be closely tied to theoretical models linking cultural influences to back pain outcomes 


\section{Conflict of interest statement}

All authors reports having no conflicts of interest related to the content of this article.

Role of the funding source

This work was carried out without funding. 
Figure 1. Commission on Social Determinants of Health framework [32]

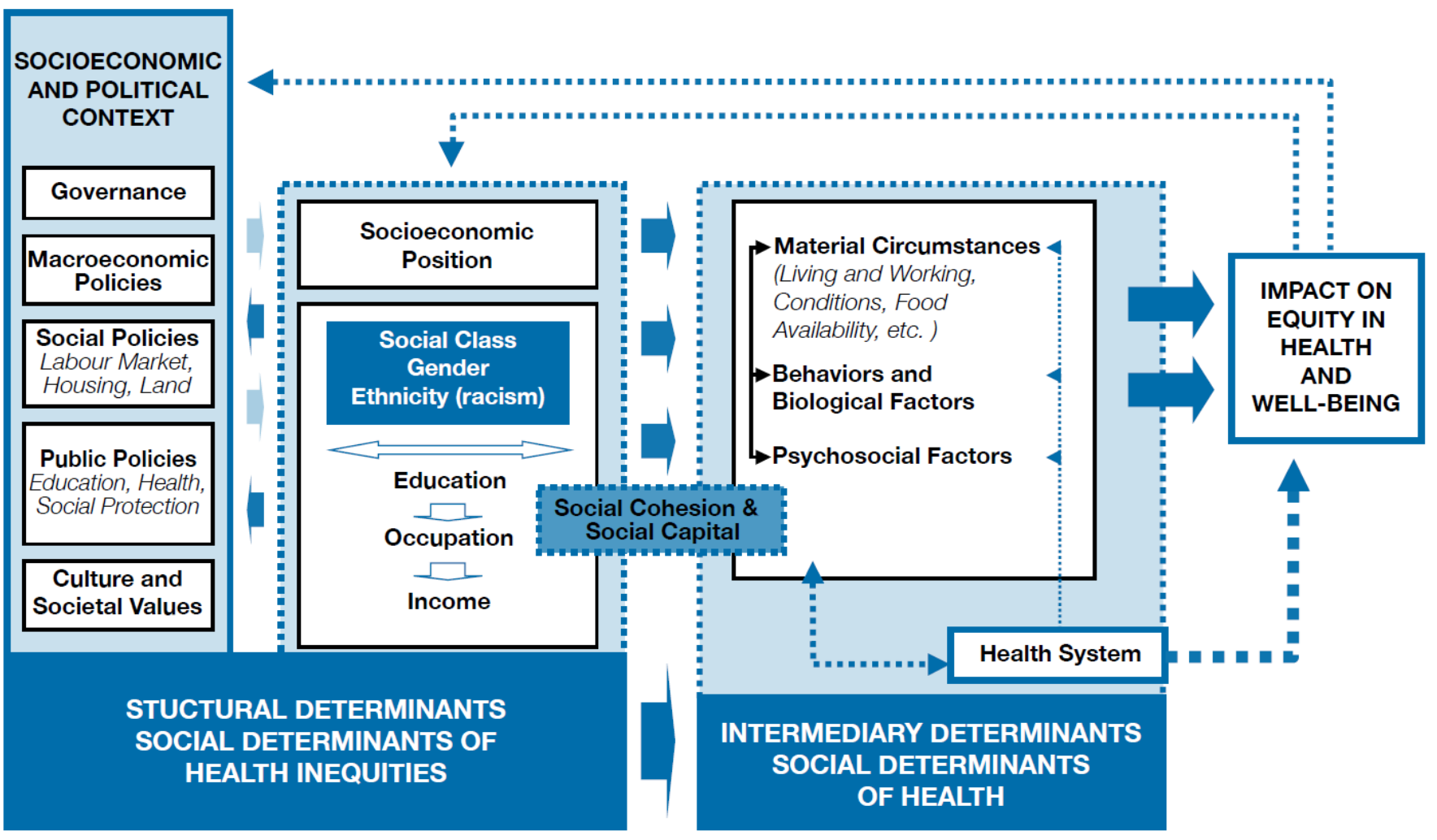


Figure 2. Prevalence of backache in adolescents by country [44].

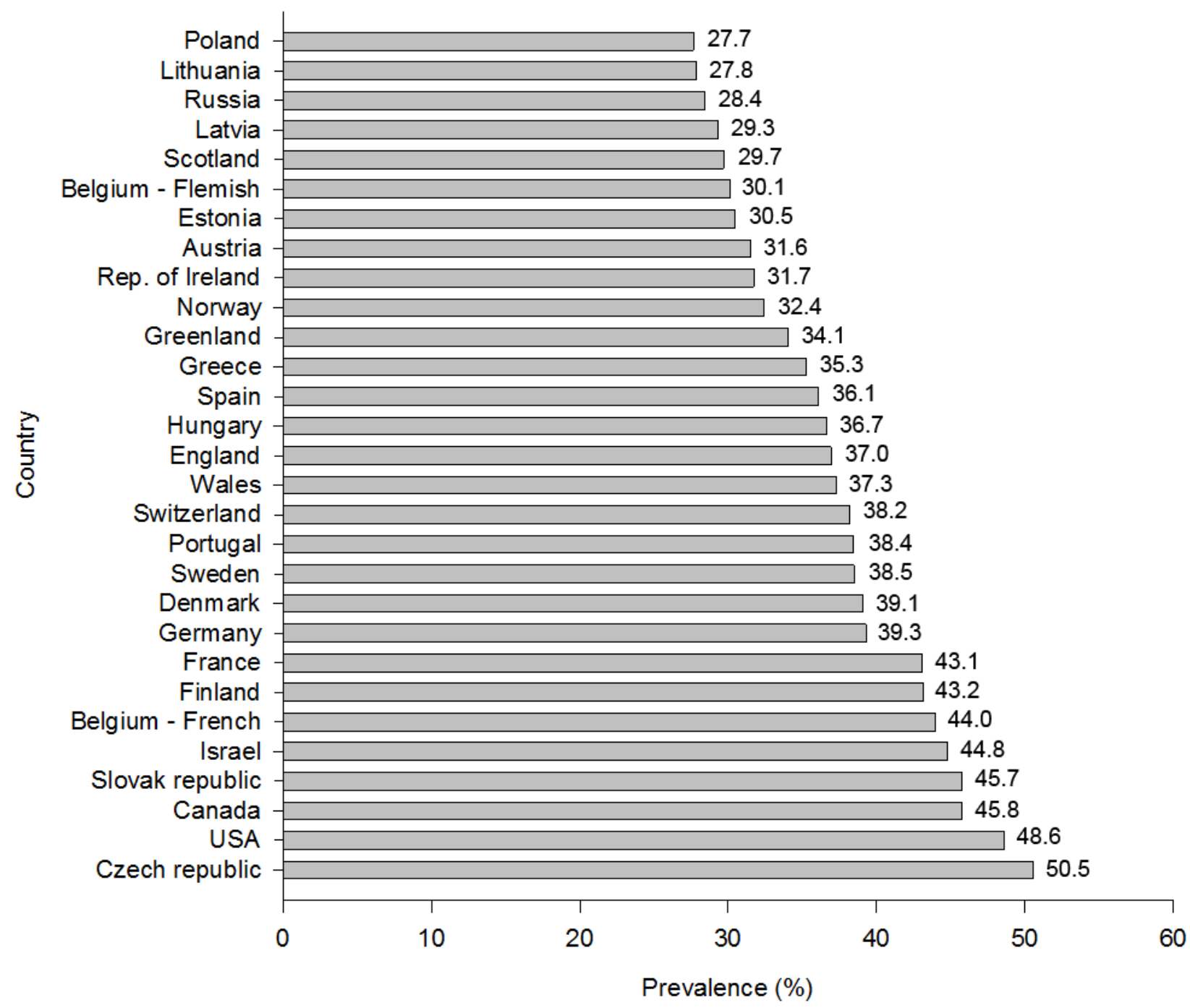




\section{References}

1. Henschke N, Kamper SJ, Maher CG. The epidemiology and economic consequences of pain. Mayo Clinic Proceedings. 2015;90(1):139-47.

2. Reid KJ, Harker J, Bala MM et al. Epidemiology of chronic non-cancer pain in Europe: narrative review of prevalence, pain treatments and pain impact. Current Medical Research \& Opinion. 2011;27(2):449-62.

3. Buchbinder R, Blyth FM, March LM et al. Placing the global burden of low back pain in context. Best Practice \& Research Clinical Rheumatology. 2013;27(5):575-89.

4. Siddall PJ, Cousins MJ. Persistent pain as a disease entity: implications for clinical management. Anesthesia \& Analgesia. 2004;99(2):510-20.

5. Aronowitz RA. When do symptoms become a disease? Annals of Internal Medicine. 2001;134(9_Part_2):803-8.

6. Williams CM, Maher CG, Latimer J et al. Efficacy of paracetamol for acute low-back pain: a doubleblind, randomised controlled trial. The Lancet. 2014;384(9954):1586-96.

7. Burton AK, Balague F, Cardon G et al. Chapter 2. European guidelines for prevention in low back pain : November 2004. Eur Spine J. 2006;15 Suppl 2:S136-68.

8. Blyth FM. Chronic pain-Is it a public health problem? Pain. 2008;137(3):465-6.

9. Goldberg DS, McGee SJ. Pain as a global public health priority. BMC public health. 2011;11(1):770. 10. Marmot M, Friel S, Bell R et al. Closing the gap in a generation: health equity through action on the social determinants of health. Lancet. 2008;372:1661-69.

11. Shaw WS, Campbell P, Nelson CC et al. Effects of workplace, family and cultural influences on low back pain: what opportunities exist to address social factors in general consultations? Best Pract Res Clin Rheumatol. 2013;27(5):637-48.

12. Blyth FM, Macfarlane GJ, Nicholas MK. The contribution of psychosocial factors to the development of chronic pain: the key to better outcomes for patients? Pain. 2007;129(1-2):8-11. 13. Napier AD, Ancarno C, Butler B et al. Culture and health. The Lancet. 2014;384(9954):1607-39. 
14. Al-Harthy M, Ohrbach R, Michelotti A, List T. The effect of culture on pain sensitivity. J Oral Rehabil. 2016;43(2):81-8.

15. Anderson KO, Green CR, Payne R. Racial and ethnic disparities in pain: causes and consequences of unequal care. The journal of pain : official journal of the American Pain Society. 2009;10(12):1187204.

16. Edwards CL, Fillingim RB, Keefe FJ. Race, ethnicity and pain. Pain. 2001;94:133-7.

17. Njobvu P, Hunt I, Pope D, Macfarlane GJ. Pain amongst ethnic minority groups of South Asian origin in the United Kingdom: a review. Rheumatology. 1999;38:1184-7.

18. UNESCO. UNESCO Universal Declaration on Cultural Diversity. 2002.

http://www.unesco.org/education/imld_2002/unversal_decla.shtml. Accessed 28th January 2017.

19. Unger JB, Schwartz SJ. Conceptual considerations in studies of cultural influences on health behaviors. Prev Med. 2012;55(5):353-5.

20. Brady B, Veljanova I, Chipchase L. Culturally informed practice and physiotherapy. J Physiother. 2016;62(3):121-3.

21. Ravindran N, Myers BJ. Cultural Influences on Perceptions of Health, Illness, and Disability: A Review and Focus on Autism. Journal of Child and Family Studies. 2011;21(2):311-9.

22. Narayan MC. Six Steps Towards Cultural Competence: A Clinician's Guide. Home Health Care Management \& Practice. 2002;14(5):378-86.

23. WHO. World Health Organization definition of Health. 1948.

http://www.who.int/about/definition/en/print.html. Accessed 28th January 2017.

24. Gurung RA. Health psychology: A cultural approach. Cengage Learning; 2013.

25. Patwardhan B, Warude D, Pushpangadan P, Bhatt N. Ayurveda and traditional Chinese medicine: a comparative overview. Evid Based Complement Alternat Med. 2005;2(4):465-73.

26. Keefe FJ, Lumley M, Anderson T et al. Pain and emotion: new research directions. Journal of clinical psychology. 2001;57(4):587-607. 
27. Brekke M, Hjortdahl P, Kvien TK. Severity of musculoskeletal pain: relations to socioeconomic inequality. Social science \& medicine. 2002;54(2):221-8.

28. Jordan KP, Thomas E, Peat $\mathrm{G}$ et al. Social risks for disabling pain in older people: a prospective study of individual and area characteristics. Pain. 2008;137(3):652-61.

29. Lacey RJ, Belcher J, Croft PR. Does life course socio-economic position influence chronic disabling pain in older adults? A general population study. The European Journal of Public Health. 2013;23(4):534-40.

30. Latza U, Kohlmann T, Deck R, Raspe H. Influence of occupational factors on the relation between socioeconomic status and self-reported back pain in a population-based sample of German adults with back pain. Spine. 2000;25(11):1390-7.

31. Eachus J, Chan P, Pearson $\mathrm{N}$ et al. An additional dimension to health inequalities: disease severity and socioeconomic position. Journal of epidemiology and community health. 1999;53(10):603-11. 32. Health CoSDo. Closing the gap in a generation: health equity through action on the social determinants of health: final report of the commission on social determinants of health. 2008. 33. Lynch JW, Smith GD, Kaplan GA, House JS. Income inequality and mortality: importance to health of individual income, psychosocial environment, or material conditions. BMJ. 2000;320:1200-4. 34. Wilkinson RG. Unhealthy societies: the afflictions of inequality. Routledge; 2002. 35. Seeman TE, Singer BH, Ryff CD et al. Social relationships, gender, and allostatic load across two age cohorts. Psychosomatic Medicine. 2002;64:395-406.

36. Dorner TE, Muckenhuber J, Stronegger WJ et al. The impact of socio-economic status on pain and the perception of disability due to pain. European Journal of Pain. 2011;15(1):103-9.

37. Blank N, Diderichsen F. Social inequalities in the experience of illness in Sweden a "double suffering". Scandinavian Journal of Public Health. 1996;24(2):81-9.

38. Lasch KE. Culture, pain, and culturally sensitive pain care. Pain Management Nursing. 2000;1(3):16-22. 
39. Shaw WS, Campbell P, Nelson CC et al. Effects of workplace, family and cultural influences on low back pain: What opportunities exist to address social factors in general consultations? Best Practice \& Research Clinical Rheumatology. 2013;27(5):637-48.

40. Henschke N, Ostelo R, van Tulder MW et al. Behavioural treatment for chronic low-back pain. Cochrane Database Syst Rev. 2010;7(7).

41. Hoy D, Bain C, Williams G et al. A systematic review of the global prevalence of low back pain. Arthritis \& Rheumatism. 2012;64(6):2028-37.

42. Hoy D, March L, Brooks P et al. The global burden of low back pain: estimates from the Global Burden of Disease 2010 study. Annals of the rheumatic diseases. 2014;73(6):968-74.

43. Louw QA, Morris LD, Grimmer-Somers K. The prevalence of low back pain in Africa: a systematic review. BMC MusculoskeletDisord. 2007;8:105.

44. Swain MS, Henschke N, Kamper SJ et al. An international survey of pain in adolescents. BMC Public Health. 2014;14(1):447.

45. Itz CJ, Geurts J, Kleef Mv, Nelemans P. Clinical course of non-specific low back pain: A systematic review of prospective cohort studies set in primary care. European journal of pain. 2013;17(1):5-15. 46. Costa LdCM, Maher CG, Hancock MJ et al. The prognosis of acute and persistent low-back pain: a meta-analysis. Canadian Medical Association Journal. 2012:cmaj. 111271.

47. Coggon D, Ntani G, Palmer KT et al. The CUPID (Cultural and Psychosocial Influences on Disability) study: methods of data collection and characteristics of study sample. PLoS One. 2012;7(7):e39820. 48. Henschke N, Maher CG, Refshauge KM et al. Prognosis in patients with recent onset low back pain in Australian primary care: inception cohort study. BMJ. 2008;337:bmj.a171.

49. Costa LC, Maher CG, McAuley JH et al. Prognosis for patients with chronic low back pain: inception cohort study. BMJ. 2009;339:b3829.

50. Buchbinder R, Jolley D, Wyatt M. Population based intervention to change back pain beliefs and disability: three part evaluation. BMJ. 2001;322(7301):1516-20. 
51. Raspe H, Hueppe A, Neuhauser H. Back pain, a communicable disease? International journal of epidemiology. 2008;37(1):69-74.

52. Macfarlane GJ, Beasley M, Smith BH et al. Can large surveys conducted on highly selected populations provide valid information on the epidemiology of common health conditions? An analysis of UK Biobank data on musculoskeletal pain. Br J Pain. 2015;9(4):203-12.

53. Melzack R. The McGill Pain Questionnaire: major properties and scoring methods. Pain. 1975;1(3):277-99.

54. Fabrega H, Tyma S. Culture, language and the shaping of illness: an illustration based on pain. Journal of Psychosomatic Research. 1976;20(4):323-37.

55. Beaton DE, Bombardier C, Guillemin F, Ferraz MB. Guidelines for the process of cross-cultural adaptation of self-report measures. Spine. 2000;25(24):3186-91.

56. Costa LO, Maher CG, Latimer J. Self-report outcome measures for low back pain: searching for international cross-cultural adaptations. Spine. 2007;32(9):1028-37.

57. Organization WH. International Classification of Functioning, Disability and Health: ICF. World Health Organization; 2001.

58. Froud R, Patterson S, Eldridge $S$ et al. A systematic review and meta-synthesis of the impact of low back pain on people's lives. BMC Musculoskelet Disord. 2014;15:50.

59. Coggon D, Ntani G, Palmer KT et al. Disabling musculoskeletal pain in working populations: is it the job, the person, or the culture? Pain. 2013;154(6):856-63.

60. Christensen U, Schmidt L, Hougaard CO et al. Socioeconomic position and variations in coping strategies in musculoskeletal pain: a cross-sectional study of 128740 -and 50-year-old men and women. Journal of Rehabilitation Medicine. 2006;38(5):316-21.

61. Green CR, Anderson KO, Baker TA et al. The unequal burden of pain: confronting racial and ethnic disparities in pain. Pain Medicine. 2003;4(3):277-94.

62. Lin IB, O'Sullivan PB, Coffin JA et al. Disabling chronic low back pain as an iatrogenic disorder: a qualitative study in Aboriginal Australians. BMJ Open. 2013;3(4). 
63. Lin IB, Ryder K, Coffin J et al. Addressing Disparities in Low Back Pain Care by Developing Culturally Appropriate Information for Aboriginal Australians: "My Back on Track, My Future". $\underline{\text { Pain }}$ Med. 2017.

64. Rodrigues-de-Souza DP, Palacios-Cena D, Moro-Gutierrez L et al. Socio-Cultural Factors and Experience of Chronic Low Back Pain: a Spanish and Brazilian Patients' Perspective. A Qualitative Study. PLoS One. 2016;11(7):e0159554.

65. Killick L, Davenport TE. Pain worlds: towards the integration of a sociocultural perspective of pain in clinical physical therapy. Physiother Res Int. 2014;19(4):193-204.

66. Davidhizar R, Giger JN. A review of the literature on care of clients in pain who are culturally diverse. International Nursing Review. 2004;51:47-55.

67. Lee TS, Sullivan G, Lansbury G. Physiotherapists' perceptions of clients from culturally diverse backgrounds. Physiotherapy.92(3):166-70.

68. Kale E, Syed HR. Language barriers and the use of interpreters in the public health services. A questionnaire-based survey. Patient Education and Counseling.81(2):187-91.

69. Lee TS, Lansbury G, Sullivan G. Health care interpreters: A physiotherapy perspective. Australian Journal of Physiotherapy. 2005;51(3):161-5.

70. Black JD, Purnell LD. Cultural competence for the physical therapy professional. Journal of Physical Therapy Education. 2002;16(1):3.

71. Beach MC, Price EG, Gary TL et al. Cultural Competency: A Systematic Review of Health Care Provider Educational Interventions. Med Care. 2005;43(4):356-73.

72. Truong M, Paradies Y, Priest N. Interventions to improve cultural competency in healthcare: a systematic review of reviews. BMC Health Services Research. 2014;14:99.

73. Lie DA, Lee-Rey E, Gomez A et al. Does cultural competency training of health professionals improve patient outcomes? A systematic review and proposed algorithm for future research. $\underline{\mathrm{J} \text { Gen }}$ Intern Med. 2011;26(3):317-25. 
74. Koes BW, van Tulder M, Lin C-WC et al. An updated overview of clinical guidelines for the management of non-specific low back pain in primary care. European Spine Journal. 2010;19(12):2075-94.

75. Lin IB, O'Sullivan P, Coffin JA et al. 'I can sit and talk to her': Aboriginal people, chronic low back pain and heathcare practitioner communication. Australian Family Physician. 2014;43(5):320-4. 76. Traeger AC, Hübscher $\mathrm{M}$, Henschke $\mathrm{N}$ et al. Effect of primary care-based education on reassurance in patients with acute low back pain: systematic review and meta-analysis. JAMA internal medicine. 2015;175(5):733-43.

77. Cowell I, McGregor A, Murtagh G et al. 'What do you think is going on': Analysis of how physiotherapists' explore patients' back pain beliefs: A conversation analytic approach. Manual Therapy. 2016;25:e114-e5.

78. Colloca L, Finniss D. Nocebo effects, patient-clinician communication, and therapeutic outcomes. Jama. 2012;307(6):567-8.

79. Darlow B, Dowell A, Baxter GD et al. The enduring impact of what clinicians say to people with low back pain. The Annals of Family Medicine. 2013;11(6):527-34.

80. Harmsen JA, Bernsen RM, Bruijnzeels MA, Meeuwesen L. Patients' evaluation of quality of care in general practice: what are the cultural and linguistic barriers? Patient Educ Couns. 2008;72(1):155-

62.

81. Oliveira VC, Refshauge KM, Ferreira ML et al. Communication that values patient autonomy is associated with satisfaction with care: a systematic review. Journal of Physiotherapy. 2012;58(4):21529.

82. Matsumoto $D$. The discrepancy between consensual-level culture and individual-level culture. Culture \& Psychology. 2003;9(1):89-95.

83. Schwartz SJ, Unger JB, Zamboanga BL, Szapocznik J. Rethinking the concept of acculturation: implications for theory and research. American Psychologist. 2010;65(4):237-51. 
84. Trickett EJ. Community psychology: Individuals and interventions in community context. Annual review of psychology. 2009;60:395-419.

85. Whitley E, Gunnell D, Dorling D, Smith GD. Ecological study of social fragmentation, poverty, and suicide. BMJ. 1999;319:1034-7. 